\title{
A Proteomic Approach to Understand MMP-3-Driven Developmental Processes in the Postnatal Cerebel- lum: Chaperonin CCT6A and MAP Kinase as Contrib- uting Factors
}

\author{
AQ6 Inge Van Hove, ${ }^{1}$ Mieke Verslegers, ${ }^{1}$ Tjing-Tjing Hu, ${ }^{2}$ Martin Carden, ${ }^{3}$ Lutgarde Arckens, ${ }^{2}$ \\ Lieve Moons ${ }^{1}$ \\ ${ }^{1}$ Laboratory of Neural Circuit Development and Regeneration, Animal Physiology and Neurobiology Sec- \\ tion, Department of Biology, KU Leuven, Leuven, Belgium \\ ${ }^{2}$ Laboratory of Neuroplasticity and Neuroproteomics, Animal Physiology and Neurobiology Section, \\ Department of Biology, KU Leuven, Leuven, Belgium \\ ${ }^{3}$ Centre for Molecular Processing and School of Biosciences, University of Kent, Canterbury, Kent, \\ AQ1 United Kingdom
}

Received 24 September 2014; revised 16 January 2015; accepted 16 January 2015

\begin{abstract}
Matrix metalloproteinase-3 (MMP-3) deficiency in mice was previously reported to result in a transiently retarded granule cell migration at postnatal day 8 (P8) and a sustained disturbed arborization of Purkinje cell dendrites from P8 on, concomitant with a delayed synapse formation between granule cells and Purkinje cells and resulting in mild deficits in motor performance in adult animals. However, the molecular mechanisms by which MMP-3 contributes to proper development of the cerebellar cortex during the first postnatal weeks remains unknown. In this study, we used a functional proteomics approach to investigate alterations in protein expression in postnatal cerebella of wildtype versus MMP-3 deficient mice, and to further eluci-
\end{abstract} be)

Correspondence to: Dr. L. Moons (Lieve.moons@bio.kuleuven.

Contract grant sponsor: Hercules Grant; contract grant number: AKUL/09/038.

Contract grant sponsor: National Grants from the Research Council of KU Leuven; contract grant numbers: KU Leuven BOFOT/10/033, GOA/12/008.

Contract grant sponsor: Research Foundation Flanders (FWO); contract grant numbers: FWO G053.10, G0335.09, G0054.12.

Contract grant sponsor: Flemish Institute for the Promotion of AQ5 Scientific Research (IWT)

(C) 2015 Wiley Periodicals, Inc.

Published online 00 Month 2015 in Wiley Online Library (wileyonlinelibrary.com).

DOI 10.1002/dneu.22272 date MMP-3-dependent pathways and downstream targets in vivo. At P8, two-dimensional difference gel electrophoresis and mass spectrometry identified 20 unique proteins with a different expression between the two genotypes. Subsequent "Ingenuity Pathway Analysis" analysis and Western blotting indicate that the chaperonin containing T-complex polypeptide 1 , subunit $6 \mathrm{~A}$ and the MAP kinase signaling pathway play a key role in the MMP-3-dependent regulation of neurite outgrowth and neuronal migration in the developing brain. () 2015 Wiley Periodicals, Inc. Develop Neurobiol 00: 000-000, 2015

Keywords: cerebellum; development; matrix metalloproteinase-3; chaperonin containing TCP-1; MAP kinase

\section{INTRODUCTION}

The postnatal mouse cerebellum forms an ideal model system to unravel and study the molecular mechanisms of brain development, and more specifically of cellular processes such as proliferation, differentiation, migration, neurite outgrowth, and synaptogenesis. In rodents, the cerebellum develops predominantly during the first 3 weeks after birth into a well-characterized structure with a limited amount 
of cell types. Novel insights into these developmental brain processes are highly required, not only for a better understanding of normal brain wiring and functioning, but also and importantly to support the search for new treatments in case of brain injuries, learning disabilities and age-related neurodegenerative brain disorders.

Matrix metalloproteinases (MMPs) are increasingly being recognized as important contributors to central nervous system (CNS) development (Yong et al., 2001; Vaillant et al., 2003; Ayoub et al., 2005; Larsen et al., 2006; Verslegers et al., 2013). Their field of action is, in contrast to their nomenclature, not restricted to proteolysis of extracellular matrix proteins, but also comprises the (in)activation of a broad range of signaling molecules, such as receptors, adhesion molecules, chemokines, cytokines, and even intracellular and intranuclear substrates (Cauwe et al., 2009; Morrison et al., 2009; Cauwe and Opdenakker, 2010). Over the past decennia, uncontrolled or unbalanced MMP activities in CNS diseases have received far more attention than their supporting role in physiological processes in the developing and adult CNS (Rosenberg, 1995, 2002; Rivera et al., 2010; Kim and Hwang, 2011). Stromelysin-1 or MMP-3 is especially known for its large degradome, mainly obtained from in vitro studies, and has been associated with several CNS disorders/injuries, for example, multiple sclerosis, glioma, stroke, Alzheimer and Parkinson's disease (Kim and Hwang, 2011). Besides, studies pointing towards its potential as a modulator of fundamental CNS physiological processes are emerging (Van Hove et al., 2012). As such, we recently reported that MMP-3 deficient (MMP- $3^{-1-}$ ) mice show an aberrant morphogenesis of the cerebellar cortex during the first postnatal weeks (Van Hove et al., 2012). More specifically, MMP-3 deficiency resulted in a delayed migration of the granule cells and GABAergic interneurons, as well as a long-lasting aberrant dendritic arborization of the Purkinje cells from postnatal day 8 (P8) on. Concomitant with a transiently disturbed synaptogenesis on these Purkinje cells, mild but sustained motor deficits could be demonstrated in adult $\mathrm{MMP}_{-} 3^{-1-}$ mice, as compared to wild-type (WT) littermates. To understand the mechanisms underlying the contribution of MMP-3 to development of the cerebellum, or the brain in general, and to provide valuable insights into (possibly new) downstream targets of MMP-3, a two dimensional fluorescence difference gel electrophoresis (2-D DIGE) approach was applied to P8 cerebella of WT and $\mathrm{MMP}^{-3^{-1}}$ mice. Twenty differential proteins were discovered after mass spectrometry analysis, and validation by Western blotting confirmed a link between T-complex protein 1 subunit zeta (CCT6a), the phosphorylation status of mitogen-activated protein kinase (MAPK, ERK1/ ERK2) and the previously described cellular phenotype in $\mathrm{MMP}-3^{-/-}$mice.

\section{MATERIALS AND METHODS}

\section{Animals}

MMP-3 deficient (MMP- $3^{-1-}$ ) and wild-type (WT) littermates from heterozygous breeding pairs $(50 \% \mathrm{Bl} 6 \times 25 \%$ B10 $\times 25 \%$ RIII) (Mudgett, Merck labs) were used for all experiments. All animals were housed under standard laboratory conditions in a 11/13h light-dark cycle with food and water ad libitum. Genotyping was performed on tail DNA with previously described primers (Van Hove et al., 2012). All animal experiments were approved by the Institutional Ethical Committee of KU Leuven and are in strict accordance with the European Communities Council Directive of 22 September 2010 (2010/63/EU).

\section{Fluorescent Two-Dimensional Difference Gel Electrophoresis}

Cerebella of MMP- $3^{-1-}(n=5)$ and WT mice $(n=5)$ were dissected at postnatal day 8 (P8), immediately frozen into ice-cold $\left(-40^{\circ} \mathrm{C}\right.$ à $\left.-50^{\circ} \mathrm{C}\right)$ isopropanol and stored at $-80^{\circ} \mathrm{C}$. To homogenize the samples, every single cerebellum was mixed with lysis buffer (7 M Urea, 2 M Thiourea, 4\% CHAPS, $40 \mathrm{mM}$ Tris base, 1\% Dithiothreitol (DTT)), supplemented with Complete Protease Inhibitor (Roche Diagnostics, Switzerland), shortly centrifuged at $13,000 \mathrm{rpm}$ and sonicated for $3 \times 25 \mathrm{~s}$. After a $1 \mathrm{~h}$ incubation at room temperature, homogenates were briefly sonicated and centrifuged at $13,000 \mathrm{rpm}$ for $20 \mathrm{~min}$ at $4^{\circ} \mathrm{C}$. Subsequently, the supernatant was dialyzed against milli-Q (Millipore) water for $2 \mathrm{~h}$ to remove residual salts, using a membrane with 500 Da cutoff (Spectra/Por, Biotech, Omnilabo). Protein concentrations were measured using the Qubit Protein Assay Kit (Invitrogen), according to the manufacturer's instructions.

The 2-D DIGE technology relies on the differential labeling of proteins with fluorescent cyanine dyes and allows for sample multiplexing and low variations. Therefore, fifty $\mu \mathrm{g}$ of each sample was labeled with the fluorescent cyanine dyes Cy3 or Cy5 and kept on ice in darkness for $30 \mathrm{~min}$. An internal standard was included to normalize across the different gels, which consists of equal amounts of every protein sample, and of which $50 \mu \mathrm{g}$ was labeled with Cy2. One $\mu \mathrm{l}$ of $10 \mathrm{mM}$ lysine was added to the samples to block the labeling reaction. After $15 \mathrm{~min}$ on ice in darkness, the Cy2-, Cy3-, and Cy5-labeled fractions were mixed together and an equal volume of lysis buffer was added. The first dimension is an isoelectric focusing, which was executed on an Ettan IPGphor Cup Loading Manifold 
system according to the manufacturer's instructions. After the run, proteins on the strip (Immobiline Drystrips, $\mathrm{pH} 3-$ 11) were equilibrated for $15 \mathrm{~min}$ in equilibration buffer $(6 \mathrm{M}$ urea, $34.5 \%(\mathrm{v} / \mathrm{v})$ glycerol and $10 \% \mathrm{w} / \mathrm{v}$ SDS in $1.5 \mathrm{M}$ Tris$\mathrm{HCl} \mathrm{pH} 8.8$ ), supplemented with $1 \%$ (w/v) DTT and subsequently alkylated for $15 \mathrm{~min}$ in equilibration buffer, supplemented with $4.5 \%$ (w/v) iodoacetamide (Sigma-Aldrich). After a brief immersion of the $\mathrm{pH}$ strips in $2 \mathrm{X}$ SDS running buffer (10X running buffer: $250 \mathrm{mM}$ Tris, $1.92 \mathrm{M}$ glycine, $1 \%$ SDS, strips were loaded onto $12.5 \%$ polyacrylamide gels. SDS-PAGE was conducted in the Ettan Dalt System (GE Healthcare), first at $30 \mathrm{~mA}$ for $30 \mathrm{~min}$ and subsequently at 15 $\mathrm{mA} / \mathrm{gel}$ overnight at $13^{\circ} \mathrm{C}$ to separate the proteins in the second dimension. Gels were imaged with the Ettan DIGE Imager 1.0 (GE Healthcare). The acquired gel image triplets (Cy2, Cy3, and Cy5) were analyzed with DeCyder 2D software (GE Healthcare). The biological variation analysis (BVA) module enables one to manually check matched spots upon automatic spot detection and matching by the DeCyder Batch processor. An independent Student's $t$-test was applied to identify the differential spots $(p<0.05)$ between MMP$3^{-1-}$ and WT cerebella.

\section{Protein Identification}

To identify the differential proteins, two-dimensional preparative gels were run in a similar way as described above, using $1 \mathrm{mg}$ of the pooled samples. Afterwards, gels were stained with Lava Purple (Gelcompany), spots of interest were automatically excised from the gels (Ettan Spot Picker, GE Healthcare), digested and spotted using a fully automated Ettan Dalt Spot Handling Workstation. In collaboration with the Centre de Recherche Public-Gabriel Lippmann in Luxemburg, MS and MS/MS spectra were acquired using a 5800 MALDI TOF-TOF (Absciex, Sunnyvale, CA), calibrated using the 4,700 peptide mass calibration kit (Applied Biosystems). Proteins were identified by searching against the NCBI database, limited to the taxonomy of Rodents (downloaded 2012.06.04, 316675 sequences), using an in-house MASCOT server (version 2.3.0 Matrix Science, www.matrixscience.com, London, U.K.). Searches were carried out defining trypsin as cleavage agent and allowing for 2 missed cleavages. A mass window of $100 \mathrm{ppm}$ was tolerated for the precursor mass and 0.75 Da for fragment ion masses. The search meters allowed for carboxymethylation of cysteine as fixed modification and oxidation of methionine and of tryptophan (double oxidation, and kynurenin formation) as variable modifications. Proteins were considered identified when two, nonoverlapping, individual peptides surpassed the peptide score threshold. When this criterion was not met, additional precursors were selected and searched using the abovedescribed parameters. $\mathrm{N}$-terminal acetylation was found by changing the cleavage to semitryptic and adding $\mathrm{N}$ terminal acetyl as variable modification.

Finally, the web-based functional analysis tool "Ingenuity Pathway Analysis" (IPA) was applied to identify the most relevant molecular networks, biological func- tions and canonical pathways for the differential proteins. The Benjamini-Hochberg multiple testing comparison method was used and a $p$-value of 0.05 was considered statistically significant.

\section{Western Blotting}

To confirm and validate the obtained 2-D DIGE data, Western blotting was carried out on a selection of biologically relevant and interesting proteins. P8 cerebella from both genotypes (WT and MMP- $3^{-1-}$ mice, $n=$ at least 5) were isolated, frozen in liquid nitrogen and homogenized in 2-D DIGE lysis buffer. Additional samples homogenized in the following lysisbuffer (50 mM Tris- $\mathrm{HCl} \mathrm{pH} 8,300 \mathrm{mM} \mathrm{NaCl}$, $0.5 \%$ NP-40, 0.5\% sodium deoxycholate, 1 mM EDTA, $\mathrm{pH} 8$ and $0.1 \%$ SDS), supplemented with 1 Complete, EDTA-free, Mini Protease Inhibitor Cocktail Tablet (Davis and Laroche) per $10 \mathrm{ml}$ lysis buffer) were also used for the detection of CCT subunits. Afterwards, cerebellar samples were sonicated for $1 \mathrm{~min}$, heated for $5 \mathrm{~min}$ at $70^{\circ} \mathrm{C}$ and centrifuged at 16,000 $g$ for $15 \mathrm{~min}$. Protein concentrations were determined by the method of Bradford using the Bio-Rad assay, measured with a spectrophotometer (Thermo Scientific) at $595 \mathrm{~nm}$ and related to a standard curve from known bovine serum albumin protein concentrations. Additional cerebellar extracts, previously applied in the 2-D DIGE experiments, were used for Western Blotting as well. Proteins were separated on 4$12 \%$ NuPage ${ }^{\circledR}$ Bis-Tris gels (Invitrogen) and transferred using the fast iBlot ${ }^{\circledR}$ Dry Blotting System (Invitrogen) onto polyvinylidene difluoride or nitrocellulose membranes. Blots were blocked for $2 \mathrm{~h}$ with $5 \%$ nonfat dry milk and incubated overnight at $4{ }^{\circ} \mathrm{C}$ with antibodies against p44/42 MAPK (1/ 500, 4695, Cell Signaling), Phospho-p44/42 mitogenactivated protein kinase (pMAPK) (1/1000, 4370, Cell Signaling) and members of the chaperonin containing TCP-1 complex (CCT), being CCT6a (1/500, sc-13896, Santa Cruz Biotechnology) and the Carden lab antibodies CCT3, CCT4, CCT6a, CCT6b (all 1/100), CCT5 (1/1000), and CCT7 (1/ 200), which were produced as described (Roobol and Carden, 1999), to peptides from the C-termini of mouse subunit sequences. After washing, the membranes were incubated with the appropriate secondary horseradish peroxidase (HRP)-conjugated secondary antibodies for $1 \mathrm{~h}$. The ChemiDoc MP Imager (Bio-Rad) was used to visualize protein bands via chemiluminescence detection (Supersignal West Dura Extended Duration Substrate, Thermo Scientific) and to measure optical densities of the protein bands and the Coomassie stain, which was used as protein loading control. Western blot analyses were performed in duplo or triplo on cerebellar extracts from at least five mice per genotype. Statistical analysis was performed using a Student's $t$-test and a $p$-value of 0.05 was considered statistically significant.

\section{Immunohistochemistry}

P8 WT mouse pups were deeply anesthetized and intracardially perfused with $4 \%$ phosphate buffered paraformaldehyde. To determine regional and cellular expression, single 


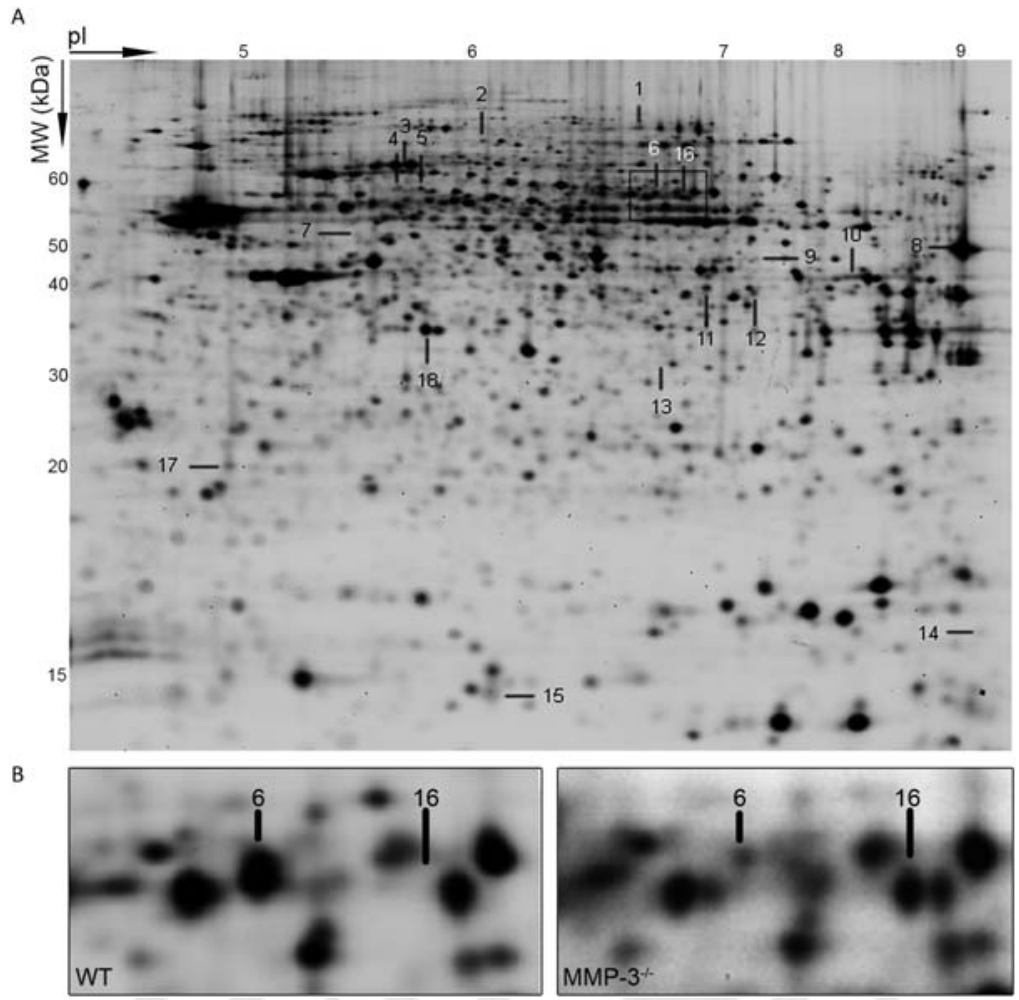

Figure 1 2-D DIGE gel images. (A) A representative grayscale 2-D DIGE overview image of the internal standard mouse cerebellar lysates separated on a $\mathrm{pH} 3-11$ (non-linear) 2-D gel. The 18 protein spots that showed statistically significant differences in fluorescence levels $(p<0.05)$ after DeCyder analysis and that were identified, are numbered on this 2-D DIGE gel. (B) Selection of the 2-D gel view showing two of the differentially expressed spots containing CCT6a, more specifically spot 6 and 16, in WT or MMP-3 $3^{-1-}$ cerebella.

and double immunofluorescent stainings were performed on $10 \mu \mathrm{m}$ sagittal cryosections, using Alexa Fluor secondary antibodies (Invitrogen) or the TSA ${ }^{\mathrm{TM}}$ FT System (PerkinElmer) in combination with the following primary antibodies: mouse anti-Calbindin-D-28K (1/1000, C9848, Sigma-Aldrich), rabbit anti-p44/42 MAPK (1/250, 4695, Cell Signaling) and rabbit anti-CCT6a (1/250, Carden lab), all as previously published (Van Hove et al., 2012; Verslegers et al., 2014). Stained sections were examined and photographed using an Olympus FV1000 confocal microscope.

\section{RESULTS}

\section{Comparative Analysis of the Cerebellar Proteome in P8 MMP $-3^{-/-}$and WT Mice}

The molecular impact of MMP-3 deficiency, previously shown to be a crucial protease for proper postnatal cerebellar development and neurite formation in the mouse (Van Hove et al., 2012), was investigated by a 2-D DIGE screen of cerebella from WT and $\mathrm{MMP}-3^{-/-}$pups at P8, the time point at which the first clear morphological differences were detected. The average ratio of the spot intensities from protein samples of P8 MMP- $3^{-/-}$and WT cerebella, randomly labeled with $\mathrm{Cy} 3$ or $\mathrm{Cy} 5$, was statistically analysed. Eighteen spots were considered significantly different when using a $p$-value of $\leq 0.05$ as cutoff (Fig. 1). Subsequent MALDI TOF/TOF analysis of the 18 spots identified 20 unique proteins, all listed in Table 1. Of note, six of the spots contained two proteins and 6 of the identified proteins were found in more than 1 spot, suggesting the presence of posttranslational modifications (PTMs) or different protein isoforms. The range in which the fluorescence levels differed between the two genotypes varied from $14 \%$ to $219 \%$. Eight of the 18 spots displayed an upregulated expression in $\mathrm{MMP}-3^{-/-}$ cerebella as compared to WT brain (Fig. 2).

To gain more insight into the biological functions and potential interactions of these 20 proteins, IPA analysis was applied. In the first subclass "molecular and cellular functions," proteins involved in cell 
Table 1 List of proteins identified by mass spectrometry that show significant changes in expression between MMP$3^{-1-}$ and WT postnatal cerebella, classified according to the ${ }^{-1-/ W T}$ ratio

\begin{tabular}{|c|c|c|c|c|c|c|}
\hline Spot no. & Protein name & Symbol & $\begin{array}{l}\text { NCBI protein } \\
\text { accession no. }\end{array}$ & $\begin{array}{c}\text { Ratio } \\
\left({ }^{-/-} /{ }^{\mathrm{WT}}\right)\end{array}$ & $p$-value & $\begin{array}{l}\text { Mowse } \\
\text { score }\end{array}$ \\
\hline 16 & T-complex protein 1 subunit zeta & ССТ6а & 6753324 & 3.19 & 0.00003 & 240 \\
\hline \multirow[t]{2}{*}{10} & Put. beta-actin & ACTB & 49868 & 1.40 & 0.032 & 269 \\
\hline & Phosphoglycerate kinase & PGK1 & 202423 & 1.40 & 0.032 & 182 \\
\hline 17 & Glyoxalase I & GLO1 & 165932331 & 1.27 & 0.016 & 90 \\
\hline \multirow[t]{2}{*}{11} & Cyclophilin-40 & PPID & 13385854 & 1.21 & 0.045 & 253 \\
\hline & $26 \mathrm{~S}$ protease regulatory subunit $\mathrm{S} 10 \mathrm{~B}$ & PSMC6 & 344245123 & 1.21 & 0.045 & 99 \\
\hline \multirow[t]{2}{*}{15} & Fatty acid-binding protein, epidermal & FABP5 & 1706754 & 1.21 & 0.013 & 66 \\
\hline & $\begin{array}{l}\text { Cytochrome c oxidase subunit 5B, } \\
\text { mitochondrial }\end{array}$ & COX5B & 117104 & 1.21 & 0.013 & 92 \\
\hline 9 & Fumarate hydratase & FH & 66968774 & 1.20 & 0.0018 & 128 \\
\hline 13 & Esterase D & ESD & 13937355 & 1.17 & 0.0004 & 49 \\
\hline 18 & L-lactate dehydrogenase B chain & LDHB & 6678674 & 1.14 & 0.028 & 489 \\
\hline 2 & $\begin{array}{l}\text { Mitochondrial inner membrane protein iso- } \\
\text { form } 3\end{array}$ & IMMT & 358439528 & -1.15 & 0.012 & 245 \\
\hline 8 & $\begin{array}{c}\text { Eukaryotic translation elongation factor } 1 \\
\text { alpha } 1\end{array}$ & EEF1a1 & 13278382 & -1.23 & 0.03 & 353 \\
\hline \multirow[t]{2}{*}{4} & Serine/threonine-protein kinase PAK 2 & PAK2 & 351694920 & -1.25 & 0.033 & 87 \\
\hline & $\begin{array}{l}\text { Dihydropyrimidinase-like 3, isoform } \\
\text { CRA_a (DPYSL3) }\end{array}$ & CRMP-4 & 148678069 & -1.25 & 0.033 & 69 \\
\hline 1 & Serotransferrin precursor & $\mathrm{TF}$ & 20330802 & -1.29 & 0.0003 & 220 \\
\hline 7 & $\begin{array}{l}\text { ATP synthase subunit beta, mitochondrial } \\
\text { precursor }\end{array}$ & ATP5B & 31980648 & -1.30 & 0.0082 & 64 \\
\hline 5 & $\begin{array}{l}\text { Dihydropyrimidinase-like 3, isoform } \\
\text { CRA_a (DPYSL3) }\end{array}$ & CRMP-4 & 148678069 & -1.37 & 0.021 & 390 \\
\hline 3 & $\begin{array}{c}\text { Dihydropyrimidinase-related protein } 2 \\
\text { (DPYSL2) }\end{array}$ & CRMP-2 & 40254595 & -1.38 & 0.03 & 564 \\
\hline 14 & $\begin{array}{l}\text { NADH dehydrogenase [ubiquinone] } 1 \\
\text { alpha subcomplex subunit } 12\end{array}$ & NDUFA12 & 47117166 & -1.46 & 0.041 & 168 \\
\hline \multirow[t]{2}{*}{12} & Cyclophilin-40 & PPID & 13385854 & -1.67 & 0.038 & 144 \\
\hline & $26 \mathrm{~S}$ protease regulatory subunit $\mathrm{S} 10 \mathrm{~B}$ & PSMC6 & 344245123 & -1.67 & 0.038 & 117 \\
\hline \multirow[t]{2}{*}{6} & $\begin{array}{l}\text { Dihydropyrimidinase-like 4, isoform } \\
\text { CRA_d (DPYSL4) }\end{array}$ & CRMP-3 & 148685898 & -1.69 & 0.00036 & 216 \\
\hline & T-complex protein 1 subunit zeta & ССТ6а & 6753324 & -1.69 & 0.00036 & 198 \\
\hline
\end{tabular}

morphology $\left(p: 1.17 \times 10^{-3}-3.56 \times 10^{-2}\right)$, cell-tocell signaling and interaction $\left(p: 1.17 \times 10^{-3}-4.57\right.$ $\left.\times 10^{-2}\right)$, and cellular assembly and organization $(p$ : $\left.1.17 \times 10^{-3}-4.90 \times 10^{-2}\right)$, were listed within the "top bio functions" and considered as relevant for the observed cerebellar phenotype in MMP- $3^{-1-}$ mice. In the second subclass "physiological system development and function," IPA analysis revealed a significant enrichment for genes involved in nervous system development and function $\left(p: 1.17 \times 10^{-3}-\right.$ $4.45 \times 10^{-2}$ ), in which most of the differential proteins were associated with neuritogenesis. Furthermore, IPA analysis considered semaphorin signaling in neurons $\left(p: 3.51 \times 10^{-7}\right)$ as the most significant "top canonical pathway." Finally, as most proteins do not act as single entities but work together in networks, IPA also unveiled 2 "top molecular networks" that represent associative network functions. The first ranked top network, in which 12 of the 20 identified proteins were involved, is "cell-to-cell signaling and interaction." A selection of this network is shown in Figure 3. Interestingly, the second top network is related to "cellular development," substantiating a role for MMP-3-related processes in cerebellar development.

\section{Confirmation and Validation of Putative MMP-3 Downstream Targets by Western Blot Analysis}

For confirmative purposes, Western blotting was performed for the molecular chaperone T-complex pro-

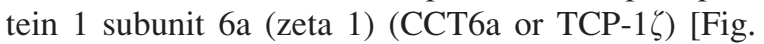




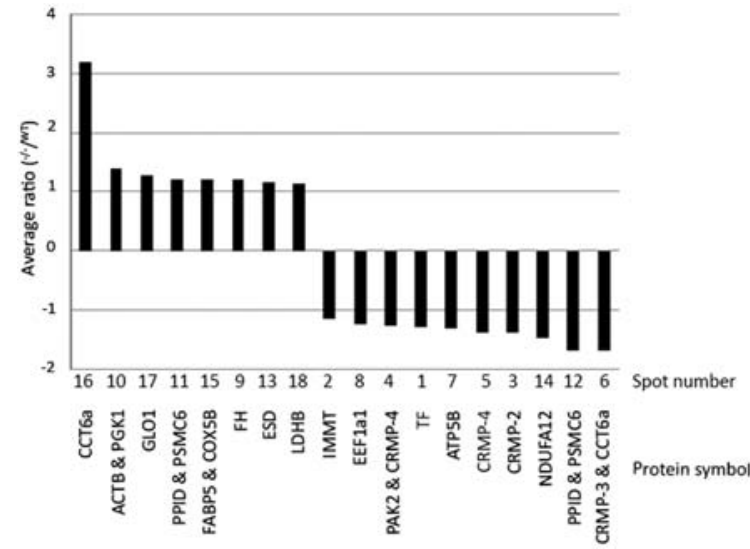

Figure 2 Graph representing the percentage differential expression of the 18 identified spots with their respective proteins. The average ratio of protein expression between MMP- $3^{-1-}$ and WT P8 cerebella reveals that, of the 18 differential spots, 8 are upregulated and 10 are downregulated in MMP- $3^{-1-}$ cerebella as compared to WT extracts. The most remarkable change in protein levels between the two conditions is assigned to CCT6a. The order of the bars matches the order of spots in Table 1.

4(A, B)]. CCT6a was chosen for validation because it is present in 2 protein spots, spot 16 and 6 , which have the highest ratio of altered expression level $\left(\mathrm{MMP}^{-1-} 3^{-1} \quad v s . \quad \mathrm{WT}\right), \quad$ respectively 3.19 $(p=0.00003)$ and $-1.69(p=0.00036)$ (Fig. 2, Table 1). As spot 6 and 16 show a shift in pI, but also a small shift in molecular weight (Fig. 1), we hypothesized that CCT6a might exist in different isoforms, as recently described by (Mukherjee et al., 2010), or/and that CCT6a might be subjected to a PTM, although the type of PTM remaining elusive (Li et al., 2006; Xiang et al., 2008; Dun et al., 2011; Miyata et al., 2014). In addition, CCT6a in spot 6 shows a higher expression in WT samples, while CCT6a in spot 16 is more abundantly present in MMP-3 $3^{-/-}$cerebella (Fig. 1, lower panels). Western blotting for CCT6a also revealed a small change in molecular weight [Fig. 4(A)]. Of note, the smaller CCT6a form is only visible in MMP- $3^{-1-}$ cerebellar samples, while CCT6a with the highest molecular weight is only detectable in WT samples, thereby confirming the 2D-DIGE data. Semiquantitative analysis further revealed a significantly reduced expression of CCT6a in MMP-3 ${ }^{-1-}$ cerebella as compared to the WT samples $(100 \pm 6.5 \%$ in WT vs. $76 \pm 3.0 \%$ in $\left.\mathrm{MMP}^{-} 3^{-/-}(n=11, p \leq 0.01)\right)$ [Fig. 4(B)]. Therefore, CCT6a seems to be differentially regulated by MMP-3, possibly by a modification at the transcriptional or/and post-translational level. CСТ6а is a member of the eukaryotic cytosolic chaperonin containing TCP-1 (CCT) complex that mediates folding of various proteins such as actin and tubulin (Fig. 3; Abe et al., 2009). To investigate whether CCT6a is the only subunit that has undergone MMP-3dependent modifications during development of the cerebellum, Western blotting was also performed for several other CCT subunits, more specifically CCT3, $4,5,6 \mathrm{~b}$, and 7 . Yet, no genotypic differences in expression level or in molecular weight could be observed for any of these CCT subunits [Figure 4(C, D)]. To evaluate whether CCT6a is expressed in the developing cerebellum, immunohistochemical stainings on the P8 mouse brain were performed and showed that CCT6a was widely expressed in various cell types throughout the cerebellar cortex, with a clear immunopositivity in the Purkinje cell somata, as revealed by double labeling with Calbindin [Fig. 6(A-C)].

According to IPA pathway analysis, mitogenactivated protein kinase 3 (MAPK3) is directly associated with CCT6a, but also with several other differentially expressed proteins from the list (Fig. 3). As such, MAPK3 provides a protein of high interest to further elucidate the pathway by which MMP-3 interacts with all these proteins, including ССТ6a, and potentially regulates the developmental processes in the cerebellum. MAPK3 (also named ERK1) constitutes, together with MAPK1 (or ERK2), the extracellular signal regulated kinase (ERK) subfamily of MAP kinases. As all known stimulants of the ERK1/ 2 pathway lead to the activation of both ERK1 and ERK2, they are mostly referred to as ERK1/2 (Roskoski, 2012). An impaired activation of the ERK1/2 signaling pathway, that implies reduced phosphorylation of the ERKs, is known to cause neurodevelopmental and behavioral deficits (Davis and Laroche, 2006; Chirivi et al., 2007; Lefloch et al., 2008; Samuels et al., 2009; Nuttall and Oteiza, 2012; Pucilowska et al., 2012). ССТ6a has been identified as a phosphoprotein and is known to contain ERK binding sites, but it is not clear yet whether CCT6a is also phosphorylated by ERK (Xiang et al., 2008; Oppermann et al., 2012; Miyata et al., 2014). Western blotting for phosphorylated, and thus activated ERK1 and ERK2, revealed a clearly stronger expression of pERK2 in comparison to pERK1 in WT cerebellar samples [Fig. 5(A)], which is in agreement with previously reported findings in mouse brain (Lefloch et al., 2008). Importantly, when comparing MMP-3 ${ }^{-/}$ to WT cerebellar samples with similar protein loading, we could observe significantly decreased expression levels of both phosphorylated ERK1 and ERK2 kinases in the absence of MMP-3, represented as average density of the pERK bands related to the density of the total protein stain $\left(2.4 \times 10^{-3} \pm 1.4 \times\right.$ 


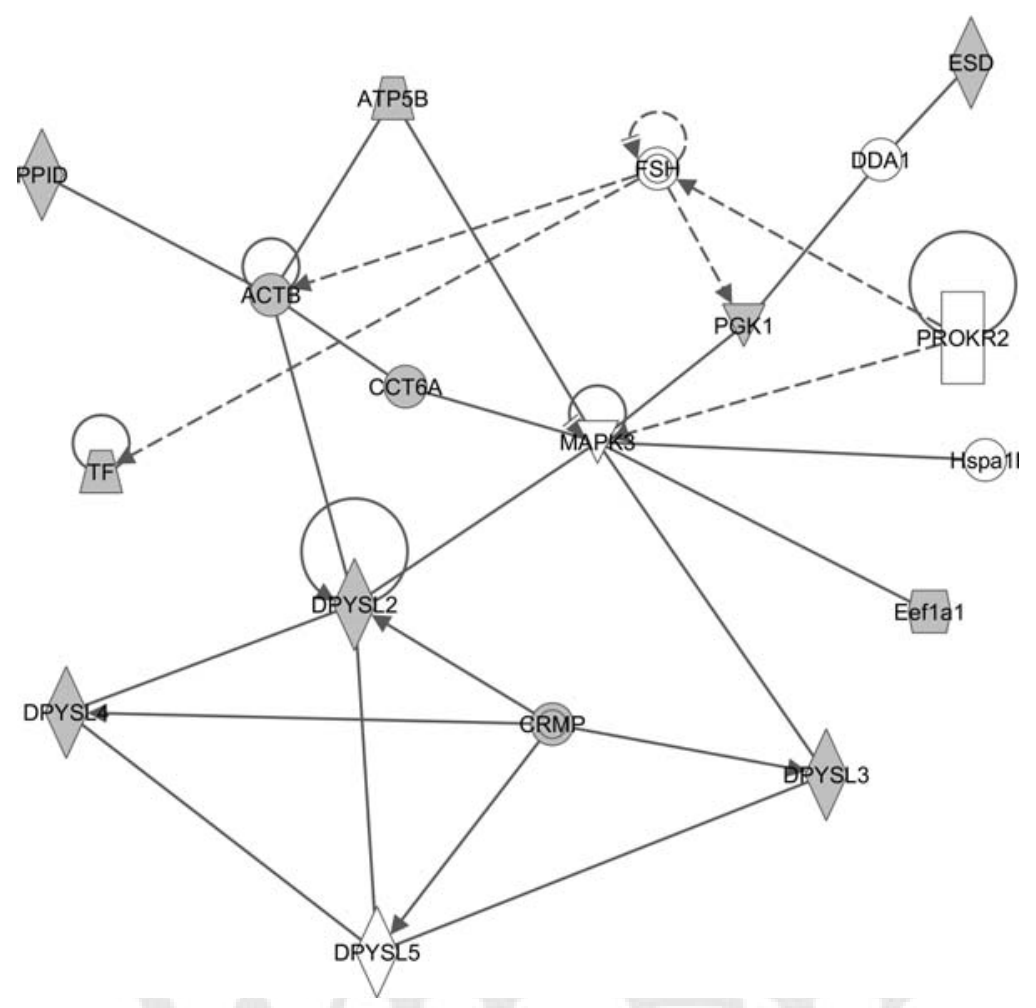

Figure 3 IPA top network of interactions of the differentially expressed proteins. The IPA tool created two protein-protein interaction networks. This graph shows a selection of proteins from the network with the highest score, "cell-to-cell signaling and interaction," and involves 11 (grey symbols) of the 20 proteins with significantly altered expression levels between MMP- $3^{-1-}$ and WT cerebella at P8. Notice how MAPK3 (ERK1) is added central to this network by the IPA software. Solid lines imply direct protein interactions while dotted lines indicate indirect relationships. (CRMP, collapsin response mediator protein; DPYSL, dihydropyrimidinase-like; Eef1a1, eukaryotic translation elongation factor 1 alpha 1; ESD, esterase D; MAPK3, mitogen-activated protein kinase 3; CCT6a, chaperonin containing TCP1, subunit 6a (zeta 1); TF, transferrin; PROKR2, prokineticin receptor 2; ACTB, actin, beta; PPID, peptidylprolylisomerase D; FSH, folliclestimulating hormone; ATP5B, ATP synthase beta; hspa11, heat shock protein 1-like; PGK1, phosphoglycerate kinase 1).

$10^{-3}$ in WT vs 0 in MMP-3 $3^{-1-}$ cerebella for pERK1 $(\mathrm{n} \geq 6, p<0.01)$, and $9.8 \times 10^{-3} \pm 2.2 \times 10^{-3}$ in WT vs $2.0 \times 10^{-3} \pm 1.5 \times 10^{-3}$ in MMP- $3^{-/-}$cerebella for pERK2 $(n \geq 7, p<0.005))$ [Fig. 5(B)]. Importantly, the expression of total ERK1/2 was not affected in the absence of MMP-3 [Fig. 5(C, D)]. Immunohistochemical stainings revealed ERK1/2 expression in all layers of the developing cerebellar cortex at $\mathrm{P} 8$, with a prominent expression in the molecular layer. Double labeling with Calbindin confirms a colocalization in Purkinje cells [Fig. 6(D-F)].

In conclusion, our observations indicate that the abnormal cerebellar development observed in postnatal MMP- $3^{-1-}$ pups might, at least partially, be due to intrinsic (and cell-to-cell) deficits in the MAP kinase signaling pathway, as shown by the reduced levels of principally phosphorylated (or activated)
ERK1 and ERK2 in MMP-3 ${ }^{-/-}$cerebella. This reduced activation of phosphorylated ERK might in turn lead to a decreased phosphorylation and/or production of the molecular chaperone CCT6a, assumed to be important for a correct cytoskeletal organization and as such, for the observed aberrant Purkinje cell dendritogenesis and/or disturbed radial granule cell migration in MMP- $3^{-1-}$ cerebella.

\section{DISCUSSION}

In this study, a 2-D DIGE approach was used to investigate changes at the proteomic level in the developing cerebellum of $\mathrm{MMP}^{-1-} 3^{-1}$ mice. The identification of altered protein levels in postnatal 
A

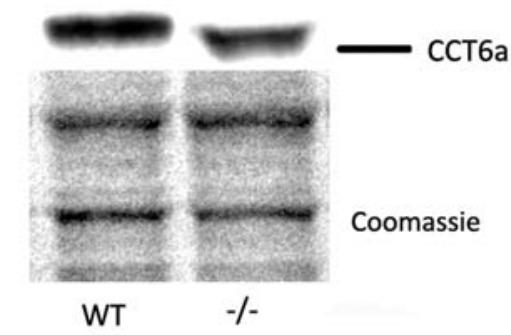

C

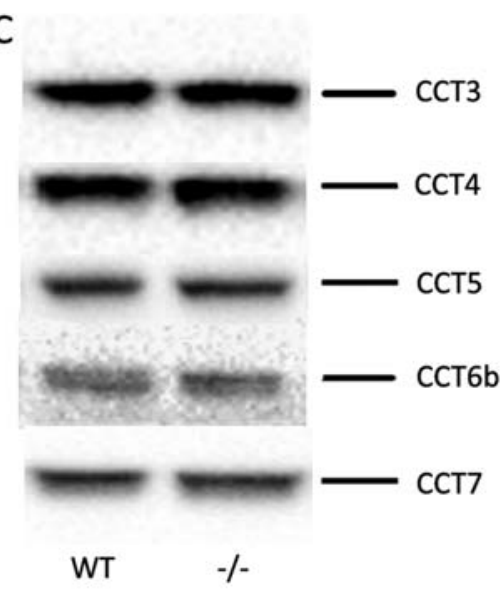

B
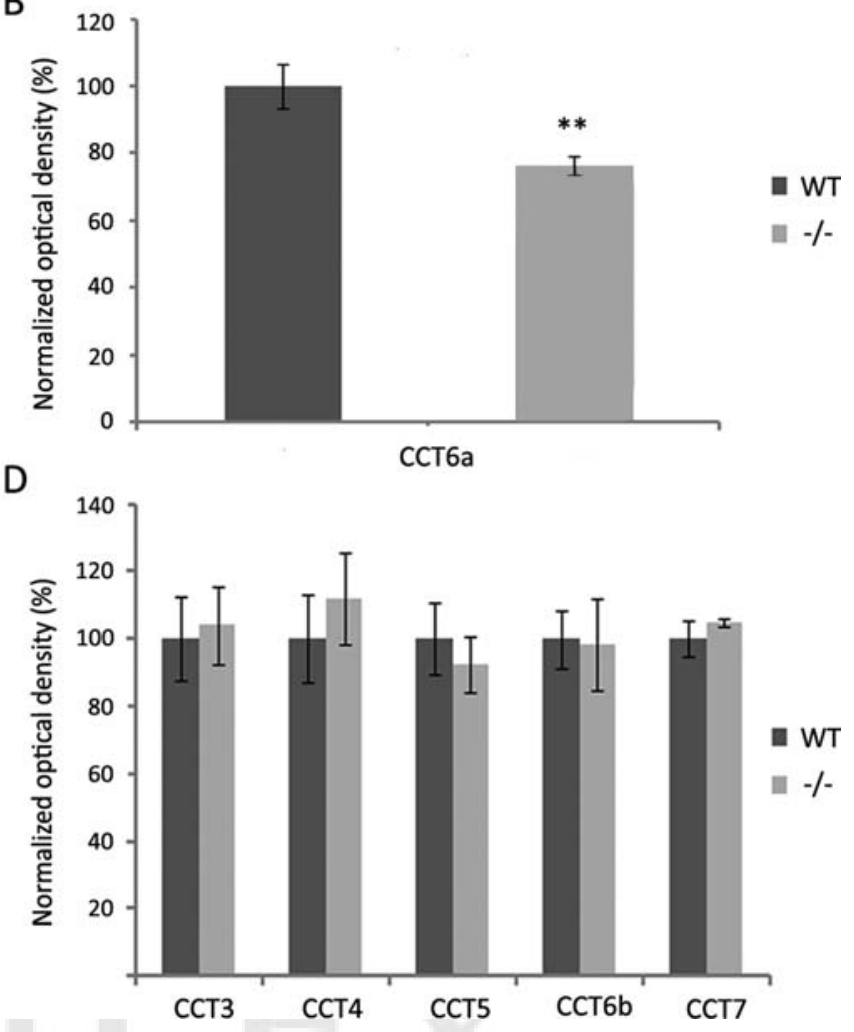

Figure 4 Western blotting for T-complex protein 1 subunits. (A) Western blotting shows that CCT6a $( \pm 58 \mathrm{kDa})$ has a lower molecular weight in $\mathrm{MMP}-3^{-1-}$ cerebella in comparison to WT cerebella. In addition, the CCT6a that is found in MMP- $3^{-1-}$ cerebella has a lower expression level. (B) Semiquantitative analysis of the CCT6a optical densities after total protein normalization confirms its significantly diminished expression in MMP- $3^{-/-}$cerebella $(n=11)$. (C) Representative Western blots for CCT3, 4, 5, 6b and 7 do not reveal any difference in molecular weight nor expression level between WT and MMP- $3^{-1-}$ cerebella. (D) Quantification of the normalized CCT subunits reveals equal protein levels between the two genotypes $(n=5)$. Data are represented as mean $\pm \mathrm{SEM} ; * * p<0.01$.

MMP- $3^{-/-}$versus WT cerebella might provide new valuable insights into MMP-3 signaling pathways and the mechanisms underlying its contribution to cerebellar development, or brain development in general. Indeed, the cerebellum serves as a highly attractive model system to study the formation and wiring of brain circuits during development and how they impact on brain functioning.

As previously described, the first morphological and anatomical aberrations in cerebellar development in MMP- $3^{-1-}$ mice could be observed from P8 on. More specifically, the cerebellar cortex of MMP- $3^{-/}$ - mice showed a delayed radial migration of granule cells and a sustained aberrant Purkinje cell dendritogenesis until adulthood (Van Hove et al., 2012). In the quest towards elucidating how MMP-3 regulates biological/physiological/cellular functions, these findings provide further information on MMP-3 related pathways and new molecular targets, supple- mental to or in confirmation of previously reported MMP-3 substrates deduced from in vitro studies (Van Hove et al., 2012). In general, a very limited amount of data exist concerning the functions and substrates of MMP-3 in the developing brain, predominantly because most research on MMP-3 has focused on its detrimental role in neural and nonneural tissues (Kim and Hwang, 2011; Van Hove et al., 2012). It should therefore not be surprising that none of the 20 proteins revealed by our proteomics study (Table 1) have been recognized before as being part of the MMP-3 degradome. However, our study requires a cautious interpretation as some of these proteins might be upregulated in the absence of MMP-3 as a compensation mechanism and therefore may not, either directly or indirectly, be part of its signaling pathways.

From the top network classified as "cell-to-cell signaling," in which most of the differential molecules 
A

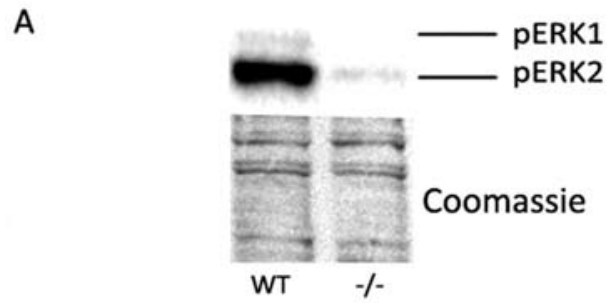

B

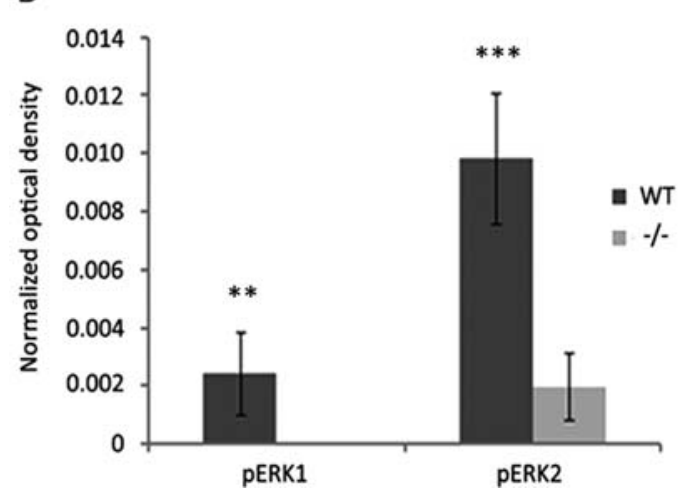

C

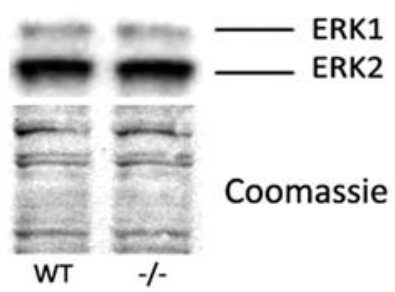

D

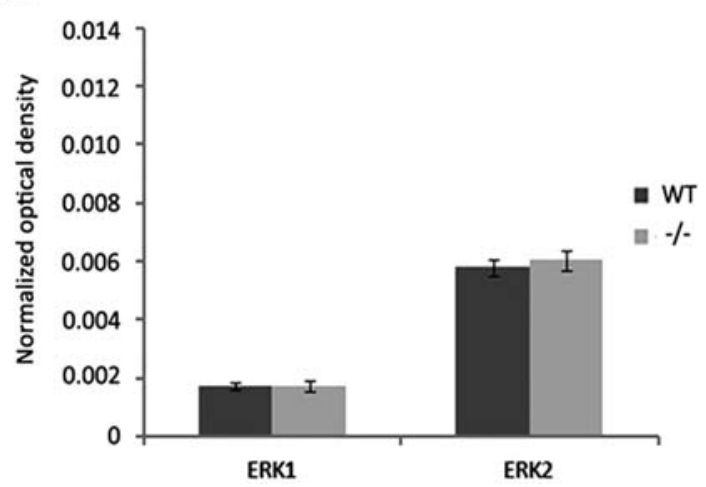

Figure 5 Expression pattern of phosphorylated and total ERK in WT and MMP-3 ${ }^{-/-}$cerebella. (A) A representative Western blot for phosphorylated MAPK3/ERK1 and MAPK1/ERK2, shows reduced bands at respectively 44 and $42 \mathrm{kDa}$ in MMP- $3^{-1-}$ samples as compared to WT cerebella. This blot also reveals that especially pERK2 is abundantly expressed in postnatal cerebella of WT mice. Coomassie blue staining served as a loading control. (B) Semiquantitative analysis confirmed that both pERK1 and pERK2 are remarkably decreased or even undetectable in MMP- ${ }^{-/-}$cerebella as compared to WT samples, when analysed at equal protein concentration. (C) Representative protein bands corresponding to total ERK1 and ERK2, as well as the loading control, are shown for the same WT and MMP- $3^{-1-}$ P8 cerebellar samples. (D) Bar graph representing semiquantitative Western blot analyses confirmed equal amounts of total ERK levels and a similar ratio of total ERK1 and ERK2 expression between WT and MMP- $3^{-1-}$ cerebella. Data are represented as mean $\pm \mathrm{SEM} ; \mathrm{n} \geq 6 ; * * p<0.01,{ }^{* * *} p<0.005$.

were interassociated, we selected the most interesting cytoskeleton-related protein that could advance our knowledge about the functional role of MMP-3 in neuronal migration and dendritogenesis, more specifically CCT6a. Of note, a parallel 2-D DIGE analysis on cerebella from WT and MMP- $3^{-1-}$ pups at P3 revealed only 5 differently expressed proteins and CCT6a was not identified as a differentially expressed protein (data not shown). These findings strengthen our previous results that also pinpoint an important role for MMP-3 in cerebellar development from the second postnatal week on (Van Hove et al., 2012).

The CCT family consists of 8 distinct subunit members $(1-8$ or $\alpha-\theta)$ of approximately $60 \mathrm{kDa}$ that constitute the chaperonin containing TCP-1 (CCT) complex, also known as the TCP-1 ring complex (TRiC). These 8 subunits with ATPase activity and a subunit-specific function form a barrel-shaped complex of two stacked eight-membered rings surrounding a central cavity that functions as a molecular chaperone, involved particularly in the correct folding of actin and tubulin. However, numerous other proteins have also been identified to interact with CCT in an ATP-dependent manner (Kubota et al., 1999; Roobol and Carden, 1999). The identification of potential CCT substrates has been increasing so far that approximately $5-10 \%$ of all newly synthesized cytoplasmic proteins seem to pass this chaperone (Yam et al., 2008). This chaperone is mainly related to cytoskeletal organization including cell cycle control, cell migration, growth cone guidance and developmental morphogenesis. Although it is clear that the heteromeric CCT oligomer is essential for the folding activity of actin and tubulin, there is increasing evidence that the CCT subunits themselves may have individual activity (Roobol and Carden, 1999; Roobol et al., 1999; Brackley and Grantham, 2009). Also CCT6a is necessary to ensure correct folding and oligomerization/polymerization of native proteins and has, according to in vitro and in vivo studies, actin and tubulin as major substrates 

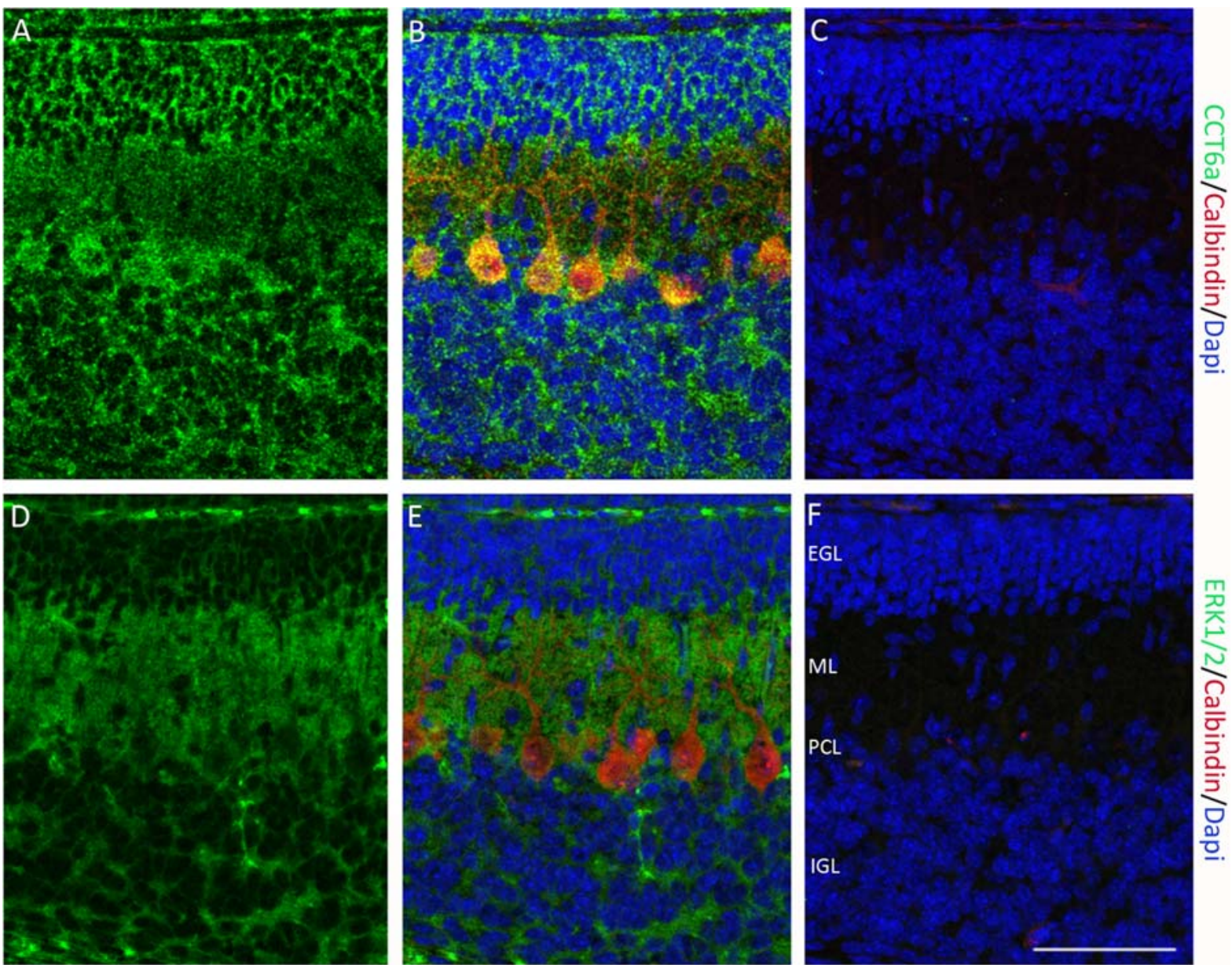

Figure 6 CCT6a and ERK1/2 expression pattern in the cerebellar cortex of WT P8 pups. (A) Immunohistochemical stainings for CCT6a reveal a uniformly stained pattern throughout the whole cerebellar cortex of P8 mouse pups, indicating its broad cellular expression. (B) Double labeling with the Purkinje cell marker Calbindin discloses CCT6a expression in the Purkinje cell somata and dendrites. (C) No labeling is seen in negative control sections (without primary antibodies for CCT6a and Calbindin), (D) ERK1/2 expression in the P8 cerebellar cortex is observed in all cerebellar layers, but especially prominent in the molecular layer, which contains the growing Purkinje cell dendrites, and migrating granule cells and inhibitory interneurons. (E) Double staining with Calbindin confirms ERK1/2 immunostaining in the Purkinje cells, especially in the dendrites. (F) Negative control sections (without primary antibodies for ERK1/2 and Calbindin) do not show any staining. (EGL, external granular layer; ML, molecular layer; PCL, Purkinje cell layer; IGL, internal granular layer). Scale bar: $100 \mu \mathrm{m}$

(Brackley and Grantham, 2009). In addition, CCT6a was found to be expressed at higher levels in the mouse forebrain at P10, in comparison to the adolescent and adult stage, as observed via 2-D DIGE (Laeremans et al., 2013). Moreover, immunohistochemical stainings on P8 mouse brain revealed CCT6a expression throughout the cerebellar cortex. As seen in the proteomics study, MMP-3 deficiency clearly affects CСТ6a expression and might thus be a modulator of CCT6a transcription and/or posttranslational modification during development. Although there are only very few quantitative studies describing PTM changes during postnatal CNS development, PTMs such as phosphorylation, acetylation and glycosylation seem to have important functions in controlling brain morphogenesis. Furthermore, recent evidence has demonstrated that specifically cytoskeletal proteins, involved in neuronal process extension and maintenance, are the most heavily modified and most frequently regulated at PTM level during mouse brain development. Interestingly, cytoskeletal proteins seem primarily regulated by phosphorylation (Goswami et al., 2012; Edwards et al., 2014). In this context, CCT2 was demonstrated 
to be phosphorylated by the ribosomal S6 kinases, RSK and S6K upon activation by the MAP kinase pathway and in response to for example, growth factors (Abe et al., 2009). CCT6a has also been identified as a phosphoprotein in adult rat ventricular myocytes subjected to diazoxide preconditioning ( $\mathrm{Li}$ et al., 2006). Recently, a phospho-proteomic approach unveiled in vivo phosphorylation sites on CCT subunits, including CCT6a, more specifically, on serine and threonine residues (Miyata et al., 2014). CCT6a has also been described to possess phosphorylation sites for MAPK/ERK, yet it is still unclear whether PTMs such as phosphorylation are necessary for this subunit to be activated (Xiang et al., 2008; Roskoski, 2012). Importantly, stimulation of PC12 cells with epidermal growth factor (EGF) or nerve growth factor (NGF) identified CCT6a as a specific component of endogenous ERK1/2 signaling complexes (von Kriegsheim et al., 2009). Although not much is known about the exact functions of the different subunits as well as the composition-related functions of this chaperone, our findings provide valuable insight into the individual function(s) of ССТ6a and its expression in the developing brain.

Since phosphorylation of the CCT complex may affect its function, we focused on a central phosphorylating enzyme in the IPA top network, MAPK3 or ERK1, related to several of the other differential proteins identified from our 2-D DIGE study by this software, more specifically eukaryotic translation elongation factor 1 alpha 1 (Eef1a1), collapsin response mediator proteins (CRMPs), phosphoglycerate kinase 1 (PGK1), ATP synthase $\beta$ (ATP5B) and CCT6a. MAPK3/ERK1 and MAPK1/ERK2 belong to the classic ERKs, which are part of an important signaling transduction cascade, the Ras/Raf/MEK/ERK pathway, which is a key pathway in transducing extracellular signals at the cell membrane into a cascade of kinase activations that ultimately phosphorylate a wide range of substrates in the nucleus, cytosol, at membranes and in cytoskeletal compartments. This pathway is involved in many basic cellular processes such as proliferation, differentiation, survival and apoptosis. Importantly, the observed incidence of phosphoregulation in cytoskeletal proteins during brain development has been, amongst others, attributed to ERK activity. In the CNS, MAPK is assumed to be abundantly present in most or all neurons and its signaling cascade has been associated with brain development, for example, cell division and differentiation, synaptic plasticity, learning and memory, emotional behaviour, etc. (Sweatt, 2001;
Tonini et al., 2006; Chirivi et al., 2007; Zhong et al., 2007; Galabova-Kovacs et al., 2008; Wefers et al., 2012; Edwards et al., 2014). Conversely, disturbances in the ERK signaling pathway have been associated with a diverse range of neurodevelopmental disorders (Weeber and Sweatt, 2002; Bentires-Alj et al., 2006; Samuels et al., 2008). For the P8 developing cerebellar cortex, we here revealed ERK1/2 expression in all layers of the cerebellum, especially in the molecular layer, which contains at this specific time point the growing Purkinje cell dendrites and migrating granule cells and inhibitory interneurons (stellate and basket cells). The observed reduction in phosphorylated ERK1/2, but not in total ERK1/2 levels, in $\mathrm{MMP}^{-1-}$ cerebellum strongly suggests that the abnormal cerebellar development in MMP- $3^{-/-}$ mice is due to intrinsic deficits in this MAPK cascade pathway. Of note, it has been reported that the MAPK pathway regulates dendritic length, but not soma size, of hippocampal neurons in culture, and that MAPK activation is required for neurite outgrowth of cerebellar neurons (Schmid et al., 2000; Jaworski et al., 2005; Kumar et al., 2005). In general, an increasing amount of studies points towards the importance of activated/phosphorylated MAPK in supporting neurite outgrowth (Hobson et al., 2006; Meng et al., 2007; Obara et al., 2009; Washio et al., 2009; Wang et al., 2011). This observation perfectly fits our previous findings on Purkinje cell morphology in $\mathrm{MMP}-3^{-/}$mice, where we also noticed a reduced dendritic tree size, but no changes in soma size, in postnatal and adult MMP-3 ${ }^{-1-}$ cerebella (Van Hove et al., 2012). Of note, also a clear reduction in apical dendritic length of pyramidal neurons has recently been demonstrated in the visual cortex of adult MMP-3 $3^{-/-}$mice (Aerts et al., 2014).

The extracellular factor, which is directly cleaved or activated by MMP-3 and subsequently initiates the MAPK pathway or rather activation (phosphorylation) of ERK1/2, remains elusive [Fig. 7(A)]. Growth factors and mitogens are among the strongest activators of ERK1/2 [Fig. 7(A)]. Yet, also electrical activity, receptor tyrosine kinases, G-protein-coupled receptors and integrins have been described to induce MAPK phosphorylation (Morrison, 2012). One of the upstream mediators of this cascade and known substrate of MMP-3 is pro-NGF, which is supposed to mediate axon outgrowth and cell survival via this pathway (Egea et al., 2000; Zhong et al., 2007). A functional interaction between MMPs and the MAPK pathway has barely been described. Most often, MMP expression can be influenced by

Developmental Neurobiology 
A

A
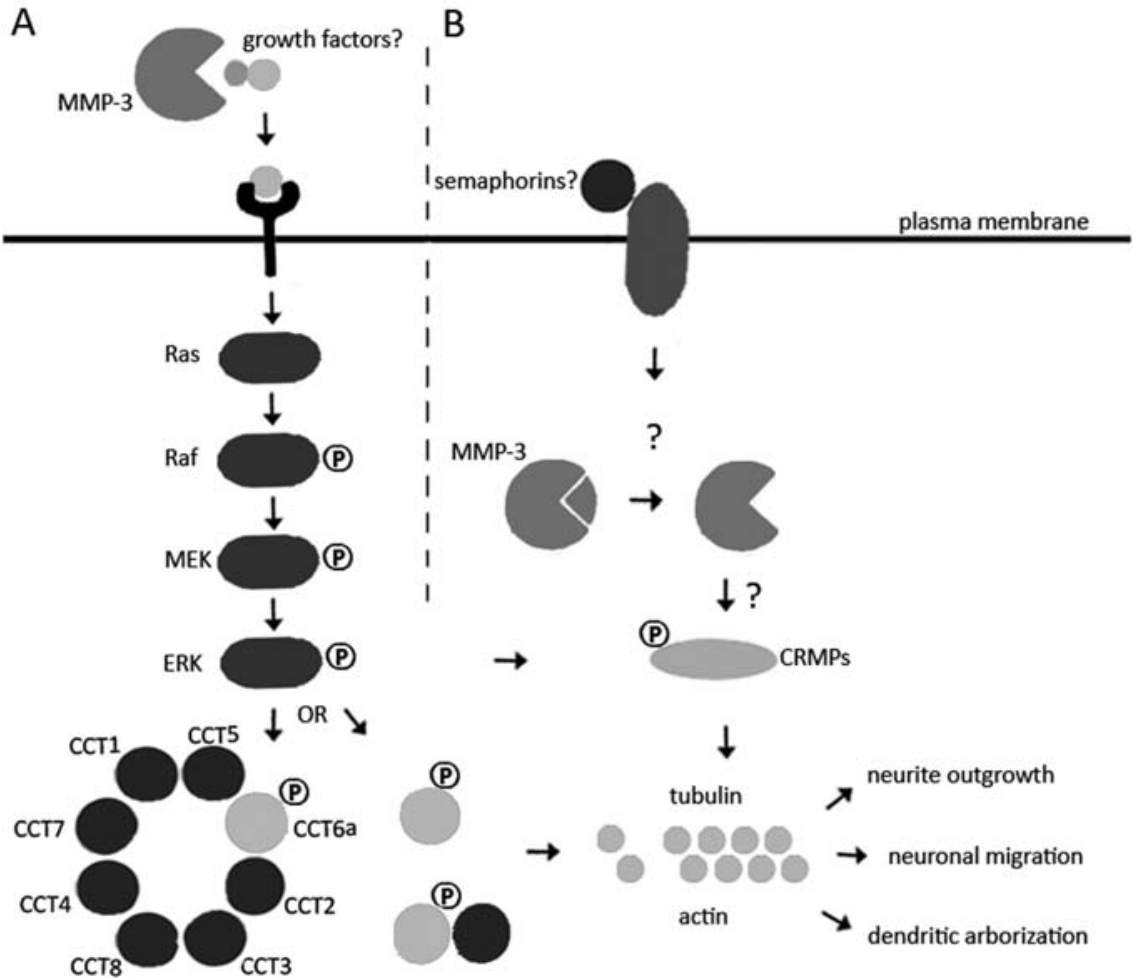

B

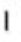

1

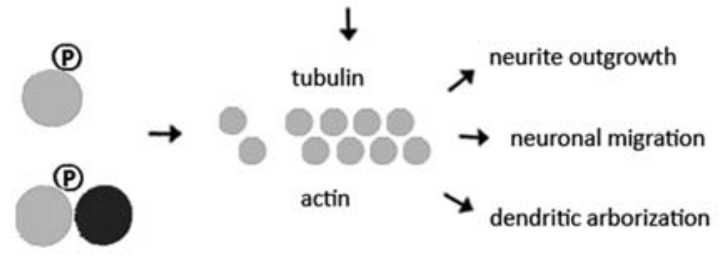

Figure 7 Schematic overview of the possible MMP-3 related molecular pathways in cerebellar development. (A) Extracellular cleavage, and thus activation, of growth factors, such as pro-NGF by MMP-3, can activate the MAP kinase signalling pathway. After binding of the growth factor to its corresponding receptor, Ras is activated and subsequently induces a kinase cascade that ultimately results in phosphorylation/activation of ERK. Subsequent phosphorylation of CCT6a, either as a component of the hetero-oligomeric chaperonin particle, as free subunits or as smaller oligomers, by ERK might result in folding of for example, actin and tubulin, both major and essential cytoskeletal cellular components. (B) Semaphorins are known regulators of MMP-3 expression and activity. As CRMPs are increasingly being recognized as members of the MMP degradome, MMP3 activation might subsequently influence CRMP activities, either directly via cleavage, or indirectly via modulating CRMP phosphorylation. CRMPs are also identified substrates of ERK1/2 and known to bind for example, actin and tubulin, thereby modulating cytoskeletal dynamics. Although hypothetical, these molecular pathways might underlie the contribution of MMP-3 to developmental processes in the brain such as neurite outgrowth, neuronal migration and dendritic arborization.

phosphorylation of transcription factors for MMPs by ERK1/2 (Kim and Lee, 2005; Mahmoodzadeh et al., 2010). However, it has been hypothesized that the $\mathrm{G}$ protein receptor kinase $(\mathrm{GRK}) / \beta$-arrestin mediated ERK activation is mediated by shedding of HB-EGF by MMPs (Dorn, 2009) [Fig. 7(A)].

With regard to the top biological functions as proposed by IPA, cellular assembly and organization and neuritogenesis can clearly be related to the previously observed findings in MMP- $3^{-/-}$mice. Moreover, semaphorin signaling in neurons, which is important in multiple developmental CNS processes, such as neuritogenesis and guidance, was demonstrated as being the most significant top canonical pathway. From the five known vertebrate CRMPs, CRMP-2-4 were differentially expressed based on the 2-D DIGE. Importantly, CRMP family members have been recognized as being downstream targets of semaphorin 3A (Schmidt and Strittmatter, 2007) and semaphorins are known regulators of MMP-3 expression/activity (Gonthier et al., 2007) [Fig. 7(B)]. In addition, CRMPs have been repeatedly reported for their contribution to brain development, and suggested to regulate cellular organization, growth cone dynamics, neurite outgrowth and dendritic patterning (Wang and Strittmatter, 1996; Arimura et al., 2005; Yoshimura et al., 2005; Yamashita et al., 2011; Tsutiya and Ohtani-Kaneko, 2012; Tan et al., 2013; Ji et al., 2014; Verslegers et al., 2014). CRMPs in turn bind actin, which is another differentially regulated protein identified in this study, and have been 
described to modulate actin bundling, thereby influencing growth cone dynamics (Arimura et al., 2005; Rosslenbroich et al., 2005; Khazaei et al., 2014) [Fig. 7(B)]. In addition, actin is also a direct client of CCT and next to growth cone steering, also importantly implicated in synaptogenesis and neurite branching (Llorca et al., 1999; Leung et al., 2006; Chia et al., 2014) (Fig. 7). From the list of differential spots, other proteins also support the previously observed phenotype in $\mathrm{MMP}-3^{-/-}$cerebella. More specifically, epidermal fatty acid binding protein (eFABP) (Liu et al., 2008; Knoferle et al., 2010; Liu et al., 2010), glyoxalase I (Kuhla et al., 2006), Eef1a1 (Hashimoto and Ishima, 2011), cyclophilin (Yuan et al., 1997), serine/threonine protein kinase (PAK2) (Shin et al., 2002; Shin et al., 2009), and so forth, have been reported to regulate neurite outgrowth/retraction, and/or neuronal migration. Notably, they are often correlated to MAPK signaling. A summarizing scheme about the possible molecular mechanisms underlying MMP-3regulated functions during brain development, including neurite outgrowth, dendritogenesis and neuronal migration, is proposed in Figure 7.

Overall, it seems plausible to conclude from our findings that MMP-3 modulates, either directly or indirectly, the intracellular MAP kinase signaling pathway and as such, influences a molecular chaperone that regulates cytoskeletal components important for neurite outgrowth, neuronal migration and dendritic arborization.

\section{ACKNOWLEDGEMENTS}

The authors thank Lieve Geenen, Ingrid Proven, Willy Van Ham and Lut Noterdaeme for their technical assistance. The authors thank Katrien Smolders for the help in interpreting the DIGE experiments. Conflict of interest: The AQ2 authors declare that they have no conflict of interest.

\section{REFERENCES}

Abe Y, Yoon SO, Kubota K, Mendoza MC, Gygi SP, Blenis J. 2009. p90 ribosomal S6 kinase and p70 ribosomal S6 kinase link phosphorylation of the eukaryotic chaperonin containing TCP-1 to growth factor, insulin, and nutrient signaling. J Biol Chem 284:14939-14948.

Aerts J, Nys J, Moons L, Hu TT, Arckens L. 2014. Altered neuronal architecture and plasticity in the visual cortex of AQ3 adult MMP-3-deficient mice. Brain Struct Funct.

Arimura N, Menager C, Kawano Y, Yoshimura T, Kawabata S, Hattori A, Fukata Y, et al. 2005. Phospho- rylation by Rho kinase regulates CRMP-2 activity in growth cones. Mol Cell Biol 25:9973-9984.

Ayoub AE, Cai TQ, Kaplan RA, Luo J. 2005. Developmental expression of matrix metalloproteinases 2 and 9 and their potential role in the histogenesis of the cerebellar cortex. J Comp Neurol 481:403-415.

Bentires-Alj M, Kontaridis MI, Neel BG. 2006. Stops along the RAS pathway in human genetic disease. Nat Med 12: 283-285.

Brackley KI, Grantham J. 2009. Activities of the chaperonin containing TCP-1 (CCT): Implications for cell cycle progression and cytoskeletal organisation. Cell Stress Chaperones 14:23-31.

Cauwe B, Martens E, Proost P, Opdenakker G. 2009. Multidimensional degradomics identifies systemic autoantigens and intracellular matrix proteins as novel gelatinase B/MMP-9 substrates. Integr Biol (Camb) 1:404-426.

Cauwe B, Opdenakker G. 2010. Intracellular substrate cleavage: A novel dimension in the biochemistry, biology and pathology of matrix metalloproteinases. Crit Rev Biochem Mol Biol 45:351-423.

Chia PH, Chen B, Li P, Rosen MK, Shen K. 2014. Local Factin network links synapse formation and axon branching. Cell 156:208-220.

Chirivi RG, Noordman YE, Van der Zee CE, Hendriks WJ. 2007. Altered MAP kinase phosphorylation and impaired motor coordination in PTPRR deficient mice. J Neurochem 101:829-840.

Davis S, Laroche S. 2006. Mitogen-activated protein kinase/extracellular regulated kinase signalling and memory stabilization: A review. Genes Brain Behav 5 (Suppl 2):61-72.

Dorn GW, 2nd. 2009. GRK mythology: G-protein receptor kinases in cardiovascular disease. J Mol Med (Berl) 87: 455-463.

Dun MD, Smith ND, Baker MA, Lin M, Aitken RJ, Nixon B. 2011. The chaperonin containing TCP1 complex (CCT/TRiC) is involved in mediating sperm-oocyte interaction. J Biol Chem 286:36875-36887.

Edwards AV, Schwammle V, Larsen MR. 2014. Neuronal process structure and growth proteins are targets of heavy PTM regulation during brain development. J Proteomics 101:77-87.

Egea J, Espinet C, Soler RM, Peiro S, Rocamora N, Comella JX. 2000. Nerve growth factor activation of the extracellular signal-regulated kinase pathway is modulated by $\mathrm{Ca}(2+)$ and calmodulin. Mol Cell Biol 20:19311946.

Galabova-Kovacs G, Catalanotti F, Matzen D, Reyes GX, Zezula J, Herbst R, Silva A, et al. 2008. Essential role of $\mathrm{B}-\mathrm{Raf}$ in oligodendrocyte maturation and myelination during postnatal central nervous system development. J Cell Biol 180:947-955.

Gonthier B, Nasarre C, Roth L, Perraut M, Thomasset N, Roussel G, Aunis D, et al. 2007. Functional interaction between matrix metalloproteinase-3 and semaphorin-3C during cortical axonal growth and guidance. Cereb Cortex $17: 1712-1721$. 
Goswami T, Li X, Smith AM, Luderowski EM, Vincent JJ, Rush J, Ballif BA. 2012. Comparative phosphoproteomic analysis of neonatal and adult murine brain. Proteomics 12:2185-2189.

Hashimoto K, Ishima T. 2011. Neurite outgrowth mediated by translation elongation factor eEF1A1: A target for antiplatelet agent cilostazol. PLoS One 6:e17431.

Hobson SA, Holmes FE, Kerr NC, Pope RJ, Wynick D. 2006. Mice deficient for galanin receptor 2 have decreased neurite outgrowth from adult sensory neurons and impaired pain-like behaviour. J Neurochem 99:10001010.

Jaworski J, Spangler S, Seeburg DP, Hoogenraad CC, Sheng M. 2005. Control of dendritic arborization by the phosphoinositide-3'-kinase-Akt-mammalian target of rapamycin pathway. J Neurosci 25:11300-11312.

Ji Z, Tan M, Gao Y, Zhang J, Gong X, Guo G, Lin H. 2014. CRMP-5 interacts with tubulin to promote growth cone development in neurons. Int J Clin Exp Med 7:6775.

Khazaei MR, Girouard MP, Alchini R, Ong Tone S, Shimada T, Bechstedt S, Cowan M, et al. 2014. Collapsin response mediator protein 4 regulates growth cone dynamics through the actin and microtubule cytoskeleton. J Biol Chem.

Kim EM, Hwang O. 2011. Role of matrix metalloproteinase-3 in neurodegeneration. J Neurochem 116:22-32.

Kim KC, Lee CH. 2005. MAP kinase activation is required for the MMP-9 induction by TNF-stimulation. Arch Pharm Res 28:1257-1262.

Knoferle J, Ramljak S, Koch JC, Tonges L, Asif AR, Michel U, et al. 2010. TGF-beta 1 enhances neurite outgrowth via regulation of proteasome function and EFABP. Neurobiol Dis 38:395-404.

Kubota H, Matsumoto S, Yokota S, Yanagi H, Yura T. 1999. Transcriptional activation of mouse cytosolic chaperonin CCT subunit genes by heat shock factors HSF1 and HSF2. FEBS Lett 461:125-129.

Kuhla B, Luth HJ, Haferburg D, Weick M, Reichenbach A, Arendt T, Munch G. 2006. Pathological effects of glyoxalase I inhibition in SH-SY5Y neuroblastoma cells. J Neurosci Res 83:1591-1600.

Kumar V, Zhang MX, Swank MW, Kunz J, Wu GY. 2005. Regulation of dendritic morphogenesis by Ras-PI3K-AktmTOR and Ras-MAPK signaling pathways. J Neurosci 25:11288-11299.

Laeremans A, Van de Plas B, Clerens S, Van den Bergh G, Arckens L, Hu TT. 2013. Protein expression dynamics during postnatal mouse brain development. J Exp Neurosci 7:61-74.

Larsen PH, DaSilva AG, Conant K, Yong VW. 2006. Myelin formation during development of the CNS is delayed in matrix metalloproteinase-9 and -12 null mice. J Neurosci 26:2207-2214.

Lefloch R, Pouyssegur J, Lenormand P. 2008. Single and combined silencing of ERK1 and ERK2 reveals their pos- itive contribution to growth signaling depending on their expression levels. Mol Cell Biol 28:511-527.

Leung KM, van Horck FP, Lin AC, Allison R, Standart N, Holt CE. 2006. Asymmetrical beta-actin mRNA translation in growth cones mediates attractive turning to netrin1. Nat Neurosci 9:1247-1256.

Li H, Xiao YB, Gao YQ, Yang TD. 2006. Comparative proteomics analysis of differentially expressed phosphoproteins in adult rat ventricular myocytes subjected to diazoxide preconditioning. Drug Metabol Drug Interact 21:245-258.

Liu JW, Almaguel FG, Bu L, De Leon DD, De Leon M. 2008. Expression of E-FABP in PC12 cells increases neurite extension during differentiation: Involvement of n-3 and n-6 fatty acids. J Neurochem 106:2015-2029.

Liu RZ, Mita R, Beaulieu M, Gao Z, Godbout R. 2010. Fatty acid binding proteins in brain development and disease. Int J Dev Biol 54:1229-1239.

Llorca O, McCormack EA, Hynes G, Grantham J, Cordell J, Carrascosa JL, Willison KR, et al. 1999. Eukaryotic type II chaperonin CCT interacts with actin through specific subunits. Nature 402:693-696.

Mahmoodzadeh S, Dworatzek E, Fritschka S, Pham TH, Regitz-Zagrosek V. 2010. 17beta-Estradiol inhibits matrix metalloproteinase-2 transcription via MAP kinase in fibroblasts. Cardiovasc Res 85:719-728.

Meng XL, Rennert OM, Chan WY. 2007. Human chorionic gonadotropin induces neuronal differentiation of PC12 cells through activation of stably expressed lutropin/choriogonadotropin receptor. Endocrinology 148:5865-5873.

Miyata Y, Shibata T, Aoshima M, Tsubata T, Nishida E. 2014. The Molecular Chaperone TRiC/CCT Binds to the Trp-Asp 40 (WD40) Repeat Protein WDR68 and Promotes Its Folding, Protein Kinase DYRK1A Binding, and Nuclear Accumulation. J Biol Chem 289:33320-33332.

Morrison CJ, Butler GS, Rodriguez D, Overall CM. 2009. Matrix metalloproteinase proteomics: Substrates, targets, and therapy. Curr Opin Cell Biol 21:645-653.

Morrison DK. 2012. MAP kinase pathways. Cold Spring Harb Perspect Biol 4.

Mukherjee K, Conway de Macario E, Macario AJ, Brocchieri L. 2010. Chaperonin genes on the rise: New divergent classes and intense duplication in human and other vertebrate genomes. BMC Evol Biol 10:64.

Nuttall JR, Oteiza PI. 2012. Zinc and the ERK kinases in the developing brain. Neurotox Res 21:128-141.

Obara Y, Yamauchi A, Takehara S, Nemoto W, Takahashi M, Stork PJ, Nakahata N. 2009. ERK5 activity is required for nerve growth factor-induced neurite outgrowth and stabilization of tyrosine hydroxylase in PC12 cells. J Biol Chem 284:23564-23573.

Oppermann FS, Grundner-Culemann K, Kumar C, Gruss OJ, Jallepalli PV, Daub H. 2012. Combination of chemical genetics and phosphoproteomics for kinase signaling analysis enables confident identification of cellular downstream targets. Mol Cell Proteomics 11:O111 012351.

Pucilowska J, Puzerey PA, Karlo JC, Galan RF, Landreth GE. 2012. Disrupted ERK signaling during cortical

Developmental Neurobiology 
development leads to abnormal progenitor proliferation, neuronal and network excitability and behavior, modeling human neuro-cardio-facial-cutaneous and related syndromes. J Neurosci 32:8663-8677.

Rivera S, Khrestchatisky M, Kaczmarek L, Rosenberg GA, Jaworski DM. 2010. Metzincin proteases and their inhibitors: Foes or friends in nervous system physiology? J Neurosci 30:15337-15357.

Roobol A, Carden MJ. 1999. Subunits of the eukaryotic cytosolic chaperonin CCT do not always behave as components of a uniform hetero-oligomeric particle. Eur J Cell Biol 78:21-32.

Roobol A, Sahyoun ZP, Carden MJ. 1999. Selected subunits of the cytosolic chaperonin associate with microtubules assembled in vitro. J Biol Chem 274:2408-2415.

Rosenberg GA. 1995. Matrix metalloproteinases in brain injury. J Neurotrauma 12:833-842.

Rosenberg GA. 2002. Matrix metalloproteinases in neuroinflammation. Glia 39:279-291.

Roskoski R, Jr. 2012. ERK1/2 MAP kinases: Structure, function, and regulation. Pharmacol Res 66:105-143.

Rosslenbroich V, Dai L, Baader SL, Noegel AA, Gieselmann V, Kappler J. 2005. Collapsin response mediator protein-4 regulates F-actin bundling. Exp Cell Res 310:434-444.

Samuels IS, Karlo JC, Faruzzi AN, Pickering K, Herrup K, Sweatt JD, Saitta SC, et al. 2008. Deletion of ERK2 mitogen-activated protein kinase identifies its key roles in cortical neurogenesis and cognitive function. J Neurosci 28:6983-6995.

Samuels IS, Saitta SC, Landreth GE. 2009. MAP'ing CNS development and cognition: An ERKsome process. Neuron 61:160-167.

Schmid RS, Pruitt WM, Maness PF. 2000. A MAP kinasesignaling pathway mediates neurite outgrowth on L1 and requires Src-dependent endocytosis. J Neurosci 20:41774188 .

Schmidt EF, Strittmatter SM. 2007. The CRMP family of proteins and their role in Sema3A signaling. Adv Exp Med Biol 600:1-11.

Shin EY, Shim ES, Lee CS, Kim HK, Kim EG. 2009. Phosphorylation of RhoGDI1 by p21-activated kinase 2 mediates basic fibroblast growth factor-stimulated neurite outgrowth in PC12 cells. Biochem Biophys Res Commun 379:384-389.

Shin EY, Shin KS, Lee CS, Woo KN, Quan SH, Soung NK, Kim YG, et al. 2002. Phosphorylation of p85 beta PIX, a Rac/Cdc42-specific guanine nucleotide exchange factor, via the Ras/ERK/PAK2 pathway is required for basic fibroblast growth factor-induced neurite outgrowth. J Biol Chem 277:44417-44430.

Sweatt JD. 2001. The neuronal MAP kinase cascade: A biochemical signal integration system subserving synaptic plasticity and memory. J Neurochem 76:1-10.

Tan M, Ma S, Huang Q, Hu K, Song B, Li M. 2013. GSK3alpha/beta-mediated phosphorylation of CRMP-2 regulates activity-dependent dendritic growth. J Neurochem 125:685-697.
Tonini R, Ciardo S, Cerovic M, Rubino T, Parolaro D, Mazzanti M, Zippel R. 2006. ERK-dependent modulation of cerebellar synaptic plasticity after chronic Delta9tetrahydrocannabinol exposure. J Neurosci 26:58105818.

Tsutiya A, Ohtani-Kaneko R. 2012. Postnatal alteration of collapsin response mediator protein 4 mRNA expression in the mouse brain. J Anat 221:341-351.

Vaillant C, Meissirel C, Mutin M, Belin MF, Lund LR, Thomasset N. 2003. MMP-9 deficiency affects axonal outgrowth, migration, and apoptosis in the developing cerebellum. Mol Cell Neurosci 24:395408.

Van Hove I, Lemmens K, Van de Velde S, Verslegers M, Moons L. 2012. Matrix metalloproteinase-3 in the central nervous system: A look on the bright side. J Neurochem 123:203-216.

Van Hove I, Verslegers M, Buyens T, Delorme N, Lemmens K, Stroobants S, Gantois I, et al. 2012. An aberrant cerebellar development in mice lacking matrix metalloproteinase-3. Mol Neurobiol 45:17-29.

Verslegers M, Lemmens K, Van Hove I, Moons L. 2013. Matrix metalloproteinase-2 and -9 as promising benefactors in development, plasticity and repair of the nervous system. Prog Neurobiol 105:60-78.

Verslegers M, Van Hove I, Dekeyster E, Gantois I, Hu TT, D'Hooge R, Arckens L, et al. 2014. MMP-2 mediates Purkinje cell morphogenesis and spine development in the mouse cerebellum. Brain Struct Funct.

von Kriegsheim A, Baiocchi D, Birtwistle M, Sumpton D, Bienvenut W, Morrice N, Yamada K, et al. 2009. Cell fate decisions are specified by the dynamic ERK interactome. Nat Cell Biol 11:1458-1464.

Wang LH, Strittmatter SM. 1996. A family of rat CRMP genes is differentially expressed in the nervous system. J Neurosci 16:6197-6207.

Wang X, Wang Z, Yao Y, Li J, Zhang X, Li C, Cheng Y, et al. 2011. Essential role of ERK activation in neurite outgrowth induced by alpha-lipoic acid. Biochim Biophys Acta 1813:827-838.

Washio A, Kitamura C, Jimi E, Terashita M, Nishihara T. 2009. Mechanisms involved in suppression of NGFinduced neuronal differentiation of PC12 cells by hyaluronic acid. Exp Cell Res 315:3036-3043.

Weeber EJ, Sweatt JD. 2002. Molecular neurobiology of human cognition. Neuron 33:845-848.

Wefers B, Hitz C, Holter SM, Trumbach D, Hansen J, Weber P, Putz B, et al. 2012. MAPK signaling determines anxiety in the juvenile mouse brain but depression-like behavior in adults. PLoS One 7: e35035.

Xiang M, Xue C, Huicai L, Jin L, Hong L, Dacheng H. 2008. Large-scale identification of novel mitosis-specific phosphoproteins. Biochim Biophys Acta 1784:882-890.

Yam AY, Xia Y, Lin HT, Burlingame A, Gerstein M, Frydman J. 2008. Defining the TRiC/CCT interactome links chaperonin function to stabilization of newly made 
proteins with complex topologies. Nat Struct Mol Biol 15:1255-1262.

Yamashita N, Mosinger B, Roy A, Miyazaki M, Ugajin K, Nakamura F, Sasaki Y, et al. 2011. CRMP5 (collapsin response mediator protein 5) regulates dendritic development and synaptic plasticity in the cerebellar Purkinje cells. J Neurosci 31:1773-1779.

Yong VW, Power C, Forsyth P, Edwards DR. 2001. Metalloproteinases in biology and pathology of the nervous system. Nat Rev Neurosci 2:502-511.
Yoshimura T, Kawano Y, Arimura N, Kawabata S, Kikuchi A, Kaibuchi K. 2005. GSK-3beta regulates phosphorylation of CRMP2 and neuronal polarity. Cell 120:137-149.

Yuan A, Mills RG, Bamburg JR, Bray JJ. 1997. Axonal transport and distribution of cyclophilin A in chicken neurones. Brain Res 771:203-212.

Zhong J, Li X, McNamee C, Chen AP, Baccarini M, Snider WD. 2007. Raf kinase signaling functions in sensory neuron differentiation and axon growth in vivo. Nat Neurosci 10:598-607. 
AQ1: Please provide the department/division name (if any) for affiliation 3.

AQ2: Please check whether acknowledgment is OK as typeset.

AQ3: Please provide complete detilas for references "Aerts et al. (2014), Khazaei et al. (2014), Verslegers et al. (2014)"

AQ4: Please provide page range for reference "Morrison (2012)."

AQ5: Please check whether grant information is OK as typeset.

AQ6: Please confirm that given names (red) and surnames/family names (green) have been identified correctly. 